\title{
LEXICAL INTERFERENCE IN NON-NATIVE RESOLUTION OF POSSESSIVES?
}

\author{
CATHRINE FABRICIUS-HANSEN, ANNELIESE PITZ, HENRIK TORGERSEN
}

\author{
University of Oslo
}

\section{ABSTRACT}

Research on non-native pronoun resolution has predominantly been concerned with (i) 'ordinary' $3^{\text {rd }}$ person pronouns/anaphors like En. he, she, they or himself, herself, themselves, (ii) language pairs involving English as the native (L1) or the foreign (L2) language, and (iii) the role that binding constraints and syntactic structure in general play in L2 versus L1 processing. The present paper - a follow-up study to Pitz et al. (2017) - deviates from this trend in all three respects: We investigate how L1-Norwegian learners of L2-German interpret the two German possessive pronouns/determiners sein $(\approx$ his) and $i h r(\approx$ her or their), arguing that lexical divergence between the possessive systems, and in particular the formal similarity between binding-neutral L2-German sein and the L1-Norwegian reflexive possessive sin, may enhance or interfere with L2 comprehension, depending on the structural conditions.

In Section 2 we briefly present the two possessive systems. Section 3 summarizes relevant research on pronoun resolution, with a special view to possessives. Sections 4-6 present a pilot study on L1-Norwegian learners' grammaticality judgments of sein and ihr in simple sentences (Sect. 5) and a forced-choice resolution experiment involving a group of L1-Norwegian learners with a background two or three years' teaching of L2-German at high-school level and a control group of native speakers of German (Sect. 6). The final Section 7 provides a summary and concluding discussion of our findings.

\section{[1] INTRODUCTION}

Possessives - e.g. determiner-like pronominal items like English his, her, its, their, or French son, leur and German sein, ihr - vary in interesting ways across even quite closely related languages (Gunkel et al. 2017: 672-719). They consequently pose different kinds of challenges to L2 acquisition, depending on the 
specific L1/L2 pair (see Sect. 3.2 below). ${ }^{1}$ The present paper - a follow-up study to Pitz et al. (2017) - is concerned with the pair L1-Norwegian/L2-German, focusing on L1-Norwegian learners' comprehension of the German $3^{\text {rd }}$ person possessives sein* and ihr*, each of which may correspond to either the reflexive possessive $s i^{*}$ or an irreflexive possessive in Norwegian. ${ }^{2}$ In addition to being neutral with respect to reflexivity like sein*, ihr* is ambiguous between (possessor) singular fem. and plural. Our study aims at testing (i) in how far the similarity between sein* and si* may enhance or disturb L1-Norwegian learners' interpretation of L2-German sein* under conditions where a reflexive reading from a grammatical point of view is either demanded or excluded, and (ii) how they resolve $i h r^{*}$ under similar conditions, given the fact that a summative plural interpretation (in the sense of Kamp \& Reyle 1993: 341-342) is also possible.

The paper is organized as follows: In Section 2 we give a brief contrastive presentation of the systems of pronominal possessives in the two languages. Section 3 summarizes relevant empirical research on pronoun and anaphor resolution, with a special view to non-native resolution and differences between possessives versus 'ordinary' pronouns. Section 4 presents the objectives and general assumption underlying two experiments that aim at testing how Norwegian $1^{\text {st }}$ year students of L2-German master the abovementioned one-tomany correspondence between possessive items in L2 grammaticality judgment (Sect. 5) and offline resolution (Sect. 6). Finally, in Section 7, we summarize the results and present some ideas for further research.

\section{[2] CONTRASTIVE BACKGROUND}

The distribution of the German $3^{\text {rd }}$ person possessives sein* and ihr* is determined by grammatical properties of their antecedent (possessor) DP: sein* demands a singular masculine or neuter possessor DP, otherwise - i.e. with singular feminine and with plural antecedents - ihr* is used. Some examples are given in (1)-(3).

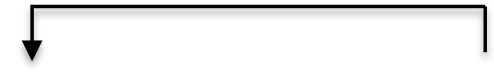
a. [Peter $]_{\text {masc.sg. }}$ hat sein Haus verkauft. 'Peter has sold his house.'
b. [Das Kind $]_{\text {neut.ss. }}$ hat sein-e Mütze verloren. 'The child has lost its cap.'

[1] In line with a widespread practice, we use the term L2 for a language that a person starts learning after childhood and after having acquired the core properties of his/her native language(s). For native speakers of Norwegian, German will normally be at least the second foreign language (L3), following after English.

[2] The star is meant to indicate that the lexical items in question are inflected in context. That is, sein*, $i h r^{*}$ and $s i^{*}$ each represent a set of inflected forms (morphological words). 
(2) a. $[\text { Lisa }]_{\text {fem.sg. }}$ hat ihr-en Wagen verkauft. 'Lisa has sold her car.'

b. [Die Wand $]_{\text {fem.sg. }}$ hat ihr-e Farbe verloren. 'The wall has lost its colour.'

(3) a. [Die Nachbarn $]_{\mathrm{pl}}$. haben ihr-e Pferde verkauft. 'The neighbours have sold their horses.'

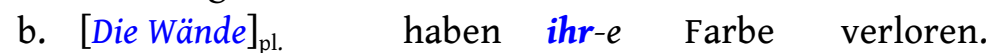
'The walls have lost their colour.'

The examples illustrate the typical adnominal function of German possessives. In this use, possessives act like determiners: They are confined to the initial functional head - position of their host DP, they inflect like determiners, agreeing with their head (possessee) noun with respect to number, gender and case; and they make their host DP semantically definite - like, e.g. English possessives (Gunkel et al. 2017: 672-719, Fabricius-Hansen et al. 2017: 12-14).

In Norwegian (bokmål), adnominal possessives have two positional options: They may occur DP-initially, as in German and English, making the DP semantically definite despite the indefinite form of the head noun; mostly, though, they are post-nominal, triggering overt definiteness marking of the preceding head noun (phrase).

Leaving differences of the inflectional systems aside, it is with respect to the nature of the possessive items and the conditions determining their use that the Norwegian and the German system of possessives differ most conspicuously (Fabricius-Hansen et al. 2017). Thus, Norwegian has a specific reflexive possessive $s i^{*}$ which, roughly speaking, must be used when the possessive is locally bound, i.e. c-commanded by an antecedent inside the local clause (typically the clause subject). ${ }^{3}$ Like the $3^{\text {rd }}$ person reflexive pronoun seg (German sich; 'his-/ herself, themselves'), $s i^{*}$ is neutral with respect to semantic/ grammatical number and gender of its antecedent; and like articles, $s i^{*}$ is inflected, agreeing in number and gender with its head noun. Examples are seen in (4)-(6), the Norwegian counterparts of (1)-(3): sin, si, sitt, sine are the singular masc./commune, singular feminine, singular neuter and plural forms of $s i^{*}$, respectively, agreeing in number and (singular) gender with the head noun, which, when preceding the possessive, exhibits corresponding forms of the definite article.

[3] Principle A in Chomsky's (1981) Binding Theory. 
(4) a. [Petter $]_{\text {masc.sg. }}$ har solgt [hus-et si-tt] $/[$ si-tt hus $]$. 'Peter has sold his house.'

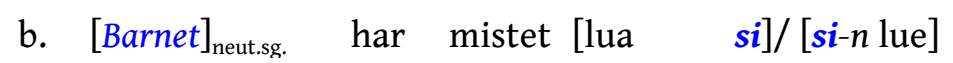
'The child has lost its cap.'

(5) a. $[\text { Lisa }]_{\text {fem.sg. }}$ har solgt $[$ bil-en $s i-n] /[s i-n$ bil $]$. 'Lisa has sold her car.'

b. [Veggen $]_{\text {comm.ss. }}$ har mistet [farg-en si- $\left.n\right] /[s i-n$ farge] 'The wall has lost its colour.'

(6) a. [Naboene $]_{\mathrm{pl} .}$ har solgt [hest-ene si-ne] / [si-ne hest-er] 'The neighbours have sold their horses.'

b. [Veggene $]_{\mathrm{pl}}$ har mistet [farg-en si-n]/[si-n farge] 'The walls have lost their colour.'

With non-local possessors, Norwegian uses genitive forms (hans 'his', hennes 'her', dens/dets 'its' and deres 'their') of $3^{\text {rd }}$ person non-reflexive - or more precisely: irreflexive - pronouns as possessives. ${ }^{4}$ As with German sein* and ihr*, the choice between these items depends solely on properties of the possessor $\mathrm{DP} /$ referent, albeit with respect to more syntactic-semantic dimensions (Fabricius-Hansen et al. 2017: 14-16). Thus, hans and hennes are used with singular human male and female possessors, corresponding to English his and her respectively; dens and dets with singular non-human possessors, corresponding to English its but differing in grammatical gender (commune vs. neuter); and deres demands a plural possessor, like English their. Examples with post-nominal hans, hennes and deres are given in (7); for dens and dets, which tend to be avoided in present day colloquial Norwegian, we refer the reader to FabriciusHansen et al. (2017).

(7) a. Mens [Jon] var borte, passet Anna katt-ene hans. 'While John was away, Anna cared for his cats.'

b. Mens [Anna] var borte, brukte Jon bil-en hennes. 'While Anna was away, John used her car.'

c. Mens [barna] var borte, malte Jon romm-etderes. 'While the children were away, John painted their room.'

[4] That is, these possessives obey Chomsky's (1981) Binding Principle B. 
By contrast, the German possessives sein* and ihr* may be locally bound, as in (1)-(3) above, or not, as in (8) below, i.e. they are neutral with respect to binding conditions (reflexivity); and the choice between them depends solely on the grammatical gender and number of the possessor DP. - Note that in (8b, c), ihr* also has a plural reading ('their'); see below.

(8) a. Während [Johan] weg war, pflegte Anna sein-e Katzen. 'While John was away, Anna cared for his cats.'

b. Während [Anna] weg war, benutzte Johan ihr-en Wagen. 'While Anna was away, John used her car.'

c. Während [die Kinder] weg waren, malte Johan ihr Zimmer. 'While the children were away, John painted their room.'

In suitable contexts, then, the German possessives may be ambiguous between a reflexive (locally bound) and non-reflexive (non-locally bound) interpretation, like English possessives. This is the case with sein in (9) below, which may be bound by the singular masc. subject (Paul) of its own clause (reflexive use, local binding) or refer to the singular masc. DP Peter occurring in the preceding clause (non-reflexive use, non-local 'binding'); that is, the host DP sein Auto 'his car' may refer to either Pauls's or Peter's car.

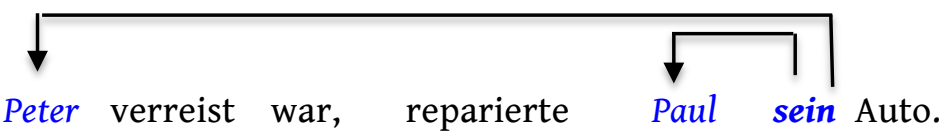

Während Peter verreist war, reparierte

'While Peter was away, Paul repaired his car.'

Likewise, ihr in (10) may be understood reflexively, referring to Lisa, or nonreflexively, referring to Anna. Moreover, ihr in (10) - and ihren in (8b) - may receive a possessor plural reading ('their'), referring to the set made up by the two different singular referents introduced in the context: Lisa + Anna in (10) and Anna + Peter in (8b). In other words, the car in (10) may belong to Lisa (full short arrow), Anna (full long arrow) or the two together (dashed arrows). Henceforth, we shall use the term summative plural interpretation for cases like these, where the plural possessor is not introduced by a single plural DP, as in (3) and ( $8 \mathrm{c})$, but 'construed over' two or more separate, non-coordinated DPs occurring in the context (see Kamp \& Reyle 1993: 341-342).

[5] In the latter case, the possessive in fact is co-referent with rather than bound by its antecedent in the strict, technical sense of the term. 


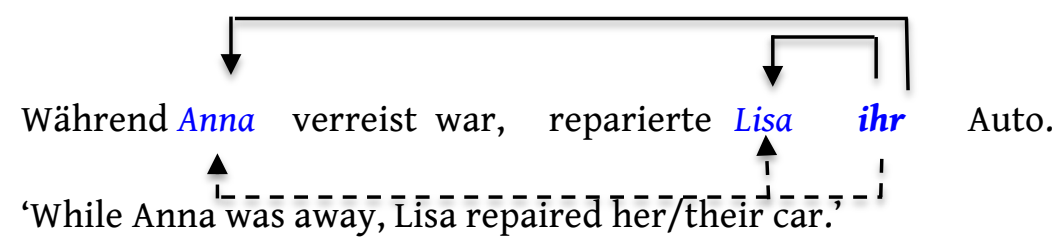

Ambiguities like the ones illustrated by full arrows in (9) and (10) do not arise in Norwegian - at least not in simple clauses like those discussed here: ${ }^{6}$ Coreference between the possessive $\left(s i^{*}\right)$ in the main clause and the subject of the subordinate clause is blocked in (11a-c) (Binding Principle A); conversely, hans 'his', hennes 'her' and deres 'their' in (12a-c) cannot refer to the subject of their own clause (Binding Principle B). Note however that deres in (12c) also allows for a summative plural interpretation, combining the referents of the two (plural) possessor 'candidates' into one (dashed arrows).

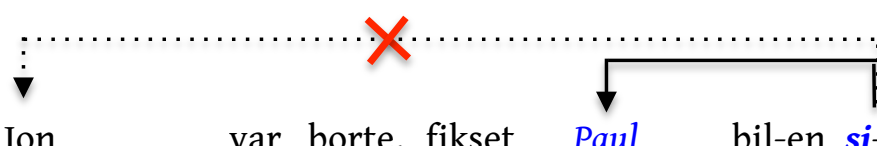

(11) a. Mens Jon var borte, fikset Paul bil-en si-n. 'While John was away, Paul fixed his (own) car.'
b. Mens Anna
var borte, fikset Lisa
bil-en si-n.

'While Anna was away, Lisa fixed her (own) car.'

c. Mens barna var borte, planla foreldrene ferie-en si-n. 'While the children were away, the parents planned their (own) holiday.'

(12)

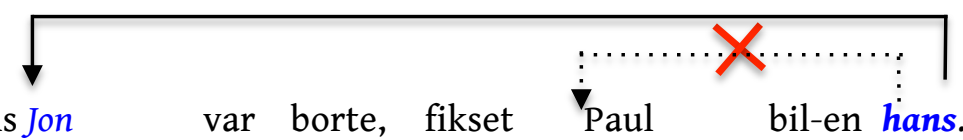
a. Mens Jon
var borte, fikset
bil-en hans.
'While John was away, Paul fixed his (Peter's) car.'
b. Mens Anna var borte, fikset Lisa bil-en hennes.

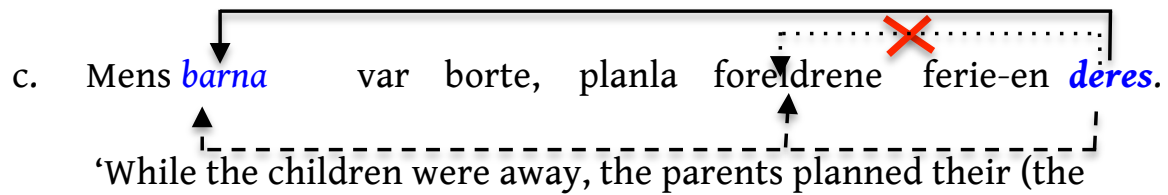

[6] In fact, things are not that neat in actual use. So-called long-distance binding is not ruled out, and on the whole, the principles governing the choice between $s i^{*}$ and the irreflexive possessives are somewhat blurred, varying across dialects, sociolects and medium (spoken and written language); see e.g. Fabricius-Hansen et al. (2017: 20-22) and references therein. In addition, even under hard-core conditions, 'errors' are not infrequent, in particular with plural possessors, i.e., deres occurring instead of 'correct' si* or vice versa. 
children's or the children's and the parents' joint) holiday.'

In short, given a thuman possessor DP, whose grammatical gender reflects the natural gender of its referent: Then $\operatorname{sein}^{*}\left(+\operatorname{sing}\right.$. male/masc.) is equivalent to $s i^{*}$ (+refl[exive]) or hans (-refl, +sing. male), depending on \pm local binding; and ihr*, being compatible with sing. fem. and plural possessors, is equivalent to $s i^{*}$ (+refl), hennes (-refl, +sing. fem.) or deres* (-refl, +plural); cf. Figure 1.
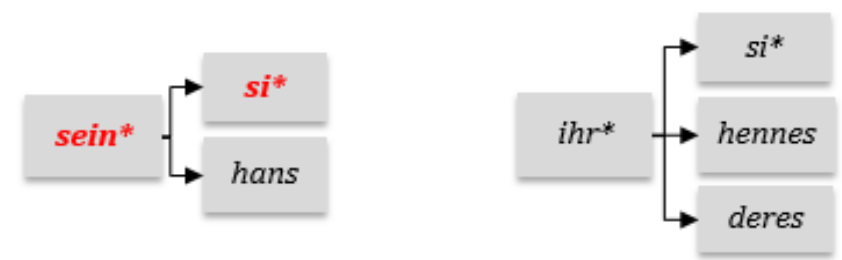

FIGURE 1: German $\rightarrow$ Norwegian lexical divergence in $3^{\text {rd }}$ person possessives with human possessor

As historical cognates, German sein* and Norwegian si* exhibit a morphophonological similarity observed in many other lexical pairs, as for instance the $1^{\text {st }}$ and $2^{\text {nd }}$ pers. singular possessives $m e i n^{*} / m i^{*}$ 'my' and $d e i n^{*} / d i^{*}$ 'your (sing.)'. Lexical divergence, then, makes sein* if not a downright 'false' so an 'unreliable friend' viewed from the perspective of L1-Norwegian users of L2-German: it may or may not be equivalent to its cognate $s i^{*}{ }^{7}$ German $i h r^{*}$, on the other hand, bears no resemblance to any of its three lexical counterparts within the system of Norwegian possessives; in addition to being neutral with respect to binding conditions/reflexivity, however, ihr* exhibits a gender-number ambiguity without parallel in the Norwegian system.

Studies conducted by Bie-Lorentzen (2012) and Pitz et al. (2017) have shown that the lack of isomorphism between the two possessive systems, as would be expected, causes problems for not very advanced Norwegian learners of L2German when translating between the two languages, whether into or from L2. The experiments presented in Sections 4-6 aim at shedding some light on how they cope with the abovementioned divergence and unreliable morphophonological similarity in offline comprehension and grammaticality judgments of L2-German possessives.

[7] According to Jarvis (2009: 107) 'false friends' may be defined as 'cross-linguistic word pairs that are (1) formally the same or similar and (2) semantically similar or dissimilar (but not the same)'. 


\section{[3.1] $3^{\text {rd }}$ person pronouns in general}

The referential interpretation of $3^{\text {rd }}$ person pronouns and other anaphoric expressions - pronoun or anaphoric resolution - is a well-established topic in theoretical linguistics (see e.g. Geurts 2011 for an overview) as well as experimental psycholinguistic investigations, a central question being how different kinds of constraints on pronouns (including reflexives) interact in native and nonnative production and comprehension of pronouns (see e.g. Nicol \& Swinney 1989; Garrod 1998; Garrod \& Terras 2000; Garnham 2000; Badecker \& Straub 2002; Kennison 2003; Sturt 2003; 2013; Koornneef 2008; Arnold 2010; Cunnings \& Felser 2013; Chow et al. 2014; Jäger et al. 2015; Patil et al. 2016; and, concerning non-native processing, e.g. Clahsen \& Felser 2006a, b; Roberts et al. 2008; Felser \& Cunnings 2012; Cunnings \& Felser 2013; Patterson et al. 2014; Colonna et al. 2014; Schimke et al. 2015; 2018; Drummer \& Felser 2018; Felser 2019; Schulz et al. 2019). ${ }^{8}$ By and large, however, possessives have got little attention (see Sect. 3.2).

A key issue in the psycholinguistic discussion is the status of structuresensitive - binding - constraints as opposed to other possible constraints on pronouns, including feature agreement between pronoun and antecedent. Do binding constraints act as a filter in native comprehension in the sense that salient but structurally inaccessible (inappropriate, illicit) antecedent candidates are immediately discarded as antecedents whether or not they match the pronoun in relevant (gender, number, ...) features (see e.g. Nicol \& Swinney 1989; Sturt 2003)? Or is a parallel cue-based resolution mechanism more plausible - a processing strategy in which 'multiple weighted constraints (including constraints on binding) simultaneously influence the net activation of a candidate during preselection stages of antecedent evaluation' (Badecker \& Straub 2002: 748)? According to Badecker \& Straub (2002), Jäger et al. (2015), Patil et al. (2016), among others, evidence on the whole seems to favor models of the latter kind.

Another question concerns resolution preferences when the context offers more than one accessible and feature-matching antecedent candidate for the anaphor, i.e. when the pronoun is referentially ambiguous. Under such conditions, local resolution (binding by Principle A) is assumed to be the preferred

[8] Note that we use the terms pronoun and anaphor in a wide sense, covering both reflexive and nonreflexive items. According to the theory of Government and Binding (Chomsky 1981), however, pronouns by definition are subject to Binding Condition B, anaphors to Condition A. In this tradition, then, lexical reflexives like him-/herself and German sich 'him-/herself, themselves') are anaphors, while he/him, she/her etc. are pronouns; see e.g. Badecker \& Straub (2002). 
choice - if structurally warranted, as for instance with sein*/ihr* in (9)/(10) (Fox 1998; Heim \& Kratzer 1998; Patterson et al. 2014). In any case, however, the interpretation in the end relies heavily on semantic, pragmatic and discourserelated cues, including the possibility of anaphoric competitors to the pronoun in question (see e.g. Bosch et al. 2007; Roberts et al. 2008; Arnold 2010: Baumann et al. 2014; Colonna et al. 2014; Schimke et al. 2015; 2018; Bader \& Portele 2019; Schulz et al. 2019).

As for non-native pronoun resolution, it is still an open question to what extent learners of a foreign language can acquire the resolution strategies and obtain the efficiency exhibited by native speakers. Studies presented by Clahsen \& Felser (2006a), Felser et al. (2009), Felser \& Cunnings (2012) and Patterson et al. (2014) indicate that L2-learners, even at an advanced level, more often consider (during processing) or even prefer (in the final interpretation) structurally inaccessible DPs as antecedents than do native comprehenders. Apparently, then, structure-sensitive constraints (Binding Principles A vs. B) do not play the same decisive role in non-native as in native pronoun resolution. Possibly, structural processing is impoverished in L2 comprehension in general. This is suggested in Clahsen \& Felser (2006a), Felser \& Cunnings (2012) and Clahsen \& Felser 2006b). However, as documented e.g. by Gast \& Haas (2008) and Patterson et al. (2014) (and as we shall see below), properties of L1 - transfer in a more or less strict sense - may also play a role. Taking stock, Felser (2019) argues that trying to reduce L1/L2 processing differences to a single cause might seem misguided.

What is called for instead is a more careful investigation of how different types of constraint and information sources interact during L2 comprehension, taking into account what linguistic cues need to be extracted from the input or need to be re-accessed in order for a given constraint to be applied. This should provide us with a more nuanced picture of how the relative weighting or timing of constraints or information sources might differ in L2 in comparison to L1 processing.

(Felser 2019: 59)

It should be added that studies on pronoun resolution predominantly concern cases where the so-called antecedent is indeed an ante-cedent, as in (1)-(15), linearly preceding the pronoun - that is, anaphoric pronouns in yet another sense of that term (cf. fn. 8). Resolution of cataphoric pronouns, which linearly precede their 'antecedent', has been studied less intensively; but see Gompel \& Liversedge (2003), Pablos et al. (2015), Drummers \& Felser (2018) and further 
references there. Online cataphoric resolution involves waiting or looking forward for - perhaps predicting - a feature-matching DP that semanticpragmatically fits into the pronoun's context. However, in order for coreference to be established between the two, they must belong to the same sentence; and according to Chomsky's (1981) Binding Condition C, the candidate DP may not be structurally bound by the pronoun. Thus Principle $C$ prevents the main clause subject he in (13a) from being resolved to the subordinate clause subject (the lord). On the other hand, as part of a DP, his in (13b) does not c-command the lord, nor can the subordinate clause subject he in $(14 \mathrm{a}, \mathrm{b})$ bind a DP within the following main clause; consequently, co-reference with the lord is possible in these three cases.

(13) a. $\boldsymbol{H e}_{i / \kappa_{j}}$ got depressed when the lord ${ }_{j}$ married the duchess.

b. His $_{i / j}$ butler got depressed when the lord $_{i}$ married the duchess.

(Drummer \& Felser 2018: 98; indices added

(14) a. When $\boldsymbol{h e}_{i / j}$ was depressed, the lord $_{j}$ invited the duchess for a drink

b. When $\boldsymbol{h e}_{i / j}$ was depressed, the duchess invited the lord ${ }_{i}$ for a drink (Drummer \& Felser 2018: 98; indices added)

Experiments conducted by Drummer \& Felser (2018) indicate that condition C plays the same role in native and non-native (Russian/German bilingual) comprehension but 'does not prevent inaccessible antecedents from being considered during the initial bonding stage', its application apparently being more 'bottom-up driven than previously thought' (Drummer \& Felser 2018: 112).

\section{[3.2] $3^{\text {rd }}$ person possessives}

Studies on the resolution of possessive pronouns are surprisingly scarce in view of the fact that possessives represent somewhat different processing challenges from ordinary personal pronouns: ${ }^{9}$

First, since possessives are determiners or modifiers in DPs, binding constraints work differently under cataphoric conditions than they do for ordinary pronouns; cf. Drummer \& Felser (2018) and Section 3.1 above.

Second, the two pronominal subsystems - ordinary and possessive $3^{\text {rd }}$ person pronouns - are not always isomorphic, as in Norwegian, but may differ in number of items and the nature or distribution of constraints. This is the case

[9] For native resolution see e.g. Kennison (2003) on (him,) his and her, Jäger et al. (2015: Sect. 4) on the Swedish possessives sin and hans, and Drummer \& Felser (2018) on the interpretation of cataphoric pronouns and possessives in subject DPs. 
in German, which has a number- and gender-neutral $3^{\text {rd }}$ person reflexive pronoun sich 'him-/her-/itself, themselves' in addition to the three number/gender-specified (irreflexive) personal pronouns (er 'he', es 'it', sie 'she/they') on the one hand and on the other hand only two possessive items (sein* and $i h r^{*}$ ), which are specified for possessor number/gender but unspecified for reflexivity (Binding Conditions A vs. B); see Sect. 1.2. English is another case in point (Kennison 2003: 337), cf. Peter ${ }_{i}$ knows himself $f_{i^{*} j}$ and Peter $_{i}$ knows him $_{\mathrm{j} / \kappa_{i}}$ vs. Peter ${ }_{i}$ knows his $\mathrm{i}_{i j \mathrm{j}}$ wife; and in French (as in other Romance languages), possessives differ from non-possessive anaphors by being underspecified not only for reflexivity but also for antecedent gender (see e.g. Helland 2017; Lago et al. 2018).

Third, in many languages, including German and e.g. French but with English as a prominent exception, adnominal possessives exhibit feature (number, gender, case, ...) agreement with the head noun of their host DP (the possessee), in addition to being specified for antecedent features. Beside searching for an antecedent (the possessor), then, comprehenders must 'keep an eye' on the possessee noun (phrase) too, checking for the relevant features; as pointed out by Lago et al. (2018), however, possessee agreement is probably a bigger problem in production than in comprehension..$^{10}$

As far as challenges to L2 acquisition are concerned, then, the grammar of adnominal possessives opens up for more variation across L1/L2 pairs than ordinary pronouns - including the relative order of possessive and possessee (cf. Sect. 1.2 above). And (the few) empirical/experimental studies on L2 production and/or comprehension of possessives indicate that even quite advanced L2 learners' performance may be influenced by their L1 possessive system in ways and to a degree that, at least in part, reflect cross-linguistic (dis)similarities in the different dimensions of possessive variation.

Santesteban et al. (2010), Foucart et al. (2011) and Antón-Méndez (2011), for instance, found that L1 speakers of a Romance language, where possessives encode gender agreement with the possessee alone, quite often use L2-English his and her in agreement with the possessee rather than the intended antecedent

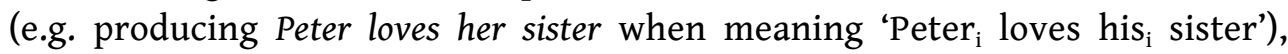
while native speakers of Greek or Dutch master the distribution of his and her like L1-English speakers, in accordance with the fact that possessives in their L1 encode gender agreement with the possessor, like English. ${ }^{11}$

[10] In addition to the factors mentioned above, the relational meaning potential of possessives, which varies somewhat across languages (cf. e.g. Baron et al. 2001; McGregor 2009; Gunkel et al. 2017: 672719), may be a complicating factor.

[11] Pozzan \& Antón-Méndez (2017) explain corresponding agreement errors made under elicited production by L1 Mandarin learners' of L2 English as resulting from a general tendency to establish local (pos- 
As for non-native comprehension of possessives, Lago et al. (2018) investigated whether multilingual speakers with either L1-English/L2-Spanish or L1Spanish/L2-English differ in their sensitivity to possessor agreement violations in German as an 'additional' non-native language ('La'), depending on whether possessor gender agreement is present in their L1 (English) or not (Spanish). Using context-free German sentences like (15a-d) in a speeded acceptability judgment and an implicit reading experiment, they found that (i) the L1Spanish participants, as expected, showed less sensitivity than the L1-English group towards possessor-possessive mismatch as displayed in (15c-d); ${ }^{12}$ (ii) high L2 proficiency may have helped L1-Spanish/L2-English in La-German but did not influence the performance of L1-English/L2-Spanish participants; (iii) contrary to their expectations, gender mismatch between possessive and possessee (Mutter 'mother'), as displayed in (15b,c) did not affect the L1-Spanish learners' performance in any significant way. ${ }^{13}$

(15) a. Frau Schmidt küsste ihre Mutter bei dem letzten Familientreffen. 'Ms. Schmidt kissed her mother at the last family reunion.'

b. Herr Schmidt küsste seine Mutter bei dem ... Familientreffen. 'Ms. Schmidt ... his mother ... .'

c. Frau Schmidt küsste seine Mutter bei dem ... Familientreffen. 'Ms. Schmidt ... his mother ... .'

d. Herr Schmidt küsste ihre Mutter bei dem ... Familientreffen. 'Ms. Schmidt ... her mother ....'

Lago et al. (2018) conclude that both the L1 grammar and the grammar of a L2 may influence multilinguals' comprehension of possessives in La and that when an agreement constraint is absent in L1, comprehenders have more difficulty deploying it in La.

The observation that L2 learners have difficulties deploying L2 constraints on possessives that are not present in their L1 is corroborated by Helland (2017), Pitz et al. (2017) and Saad et al. (2019) with respect to the structuresensitive binding constraints (Condition A vs. B) that characterize reflexive vs. irreflexive possessive markers.

sessive-possessee) agreement. But this hypothesis cannot account for the abovementioned difference between L1-Romance and L1-Dutch or Greek learners' performance; cf. Lago et al. (2018).

[12] Note that (15c) and (15d) are ungrammatical only under a locally bound/ reflexive reading of the possessive.

[13] It might have played a role that the Spanish $3^{\text {rd }}$ person (singular) possessive $s u$ 'his, her', in contrast to $1^{\text {st }}$ and $2^{\text {nd }}$ person possessives, is in fact neutral with respect to possessee gender; see the discussion in Lago et al. (2018). 
Saad et al. (2019) investigated how well multilingual speakers whose first (majority) language (Austronesian Alor Malay) has binding-neutral $3^{\text {rd }}$ person possessive marking master the distinction between reflexive and irreflexive $3^{\text {rd }}$ person possessive marking in their second (minority) language (Indonesian Abui). They found that (pre-)adolescents did not fully master the distinction, whether in production or comprehension, and that the tendency was to overgeneralize the irreflexive prefix to reflexive contexts rather than the other way around, arguably because the former, being less restricted, is considerably more frequent in natural discourse.$^{14}$ Notably, possessive marking in L1-Malay bears no morpho-phonological resemblance to either the reflexive or the irreflexive possessive marking in L2-Abui.

Turning to Norwegian versus German (Bie-Lorentzen 2012; Pitz et al. 2017) or French (Helland 2017), things become more complicated since (i) possessive systems in Norwegian and German or French differ with respect to featureagreement constraints in addition to the structure-sensitive binding constraint, and (ii) in particular because the Norwegian reflexive $s$-possessive $(\sin / \mathrm{si} / \mathrm{sitt} / \mathrm{sine})$ is an 'unreliable friend' of its binding-neutral $s$-cognates in German (sein*; see Sect. 1.2) and French (son/sa/ses; Helland 2017). Consequently, incorrectly assigning a non-local antecedent to $\mathrm{L} 2 \mathrm{si}^{*}$, whether in production or comprehension, may be due to more or less shallow (negative) transfer priming - from L1-German sein* (or L1-French $s^{*}$ ) rather than insufficient mastering of the binding constraints on the L2-Norwegian possessives. ${ }^{15}$ Likewise, when L1-Norwegian learners of L2-German understand German sein* as locally bound (reflexive) under conditions that grammatically preclude such an interpretation, or erroneously use sein* instead of $i h r^{*}$ under local binding, this may be due to interference from $s i^{*}$ rather than insufficient mastering of agreement constraints or nominal gender in German.

The results of translation tests ( $\mathrm{L} 1 \rightarrow \mathrm{L} 2$ and $\mathrm{L} 2 \rightarrow \mathrm{L} 1)$ conducted by BieLorentzen (2012) and Pitz et al. (2017) indicate that the cross-linguistic divergence of sein* into $\mathrm{si}^{*}$ and hans, hennes, deres and the divergence of $s i^{*}$ into $\operatorname{sein}^{*}$ and $i h r^{*}$, as expected, constitute an obstacle for L1-German learners of L2Norwegian and L1-Norwegian learners of L2-German, respectively, and that '[i]n both cases, there seemed to be a tendency to translate on the basis of the L1 system although morpho-phonological priming cannot be ruled out' (Pitz et al. 2017: 69). The study presented below, however, is the first to investigate L1Norwegian learners' comprehension of the L2-German possessives sein* and ihr* in tasks that do not involve translation.

[14] It may be asked whether the forced choice task intended to test comprehension is indeed a comprehension task rather than some kind of restricted elicitation task.

[15] See e.g. Jarvis (2009); ZhaoHong \& Tarone (2014); and Yu \& Odlin (2016) on the notion of transfer. 
[4] THE PRESENT STUDY: AIM AND GENERAL ASSUMPTION

We have seen that the German possessives sein* and ihr* (with a +human antecedent) pose at least three potential challenges to Norwegian learners:

(i) They are unspecified with respect to binding conditions and consequently may exhibit a type of referential (reflexive/non-reflexive) ambiguity that, at least under 'hard-core' conditions (see fn. 6), is excluded for Norwegian possessives (Sect. 1.2).

(ii) Being binding-neutral but morpho-phonologically similar, sein* is an 'unreliable friend' of the Norwegian reflexive possessive si* (cf. Fig. 1)

(iii) Beyond being binding-neutral, ihr* is ambiguous between (possessor) singular fem. and plural (cf. Fig. 1).

Our study focuses on Norwegian learners' interpretation of sein* and ihr* under conditions where sein* according to the rules of German grammar in the given (empty) context either must be or cannot be locally bound, as for instance in (1)-(2) and (8) respectively; and likewise for $i h r^{*}$ if understood as singular. That is, leaving locality-ambiguities caused by (i) aside, we are specifically interested in the possible effects of (ii) and (iii) on Norwegian speakers' grammaticality judgments and, in particular, (off-line) comprehension of L2 sein* and ihr*. The learners we are concerned with are $1^{\text {st }}$ year L1-Norwegian university students of German who have had two or three years' non-immersed teaching of German as a foreign language at high school level, corresponding to level B1 and B2 respectively of the CEFR (Common European Framework of Reference for Languages). They all had English as their first foreign language.

Due to (ii) and in line with Pitz et al. (2017), we assume that Norwegian learners of L2-German at this level of proficiency tend to associate sein* more strongly with $s i^{*}$ than with hans. Consequently, they should be more prone to wrongly understand and judge unambiguously non-locally bound sein* as locally bound $\left(\approx s i^{*}\right)$ than to understand and judge unambiguously locally bound sein* as non-locally bound ( $\approx$ hans). This is one of the main assumptions underlying the experiments presented in Sections 5 and 6 .

Due to (iii), we expect the pattern of interpretation and grammaticality judgment among Norwegian learners - and native speakers of German as well to be more diffuse/ less skewed for ihr* than for sein*.

As for the inherent reflexive/non-reflexive ambiguity of ihr*, Pitz et al. (2017) speculate that the morpho-phonological dissimilarity between $i h r^{*}$ and its reflexive Norwegian counterpart $s i^{*}$, which contrasts with the $s e i{ }^{*} / s i^{*}$ pair, 
may 'push' the Norwegian learners towards associating ihr* more strongly with its irreflexive Norwegian counterparts hennes (sing. fem.) and deres (plur.) than with $s i^{*}$. In that case, they would be expected to misinterpret and judge unambiguously locally bound $i h r^{*}$ as non-locally bound ( $\approx$ hennes or deres) more often than the other way around - and more often than would be expected for sein*. It may be asked, however, whether the effect is counteracted by a default preference for the local candidate under locality-ambiguous conditions (cf. Sect. 3.1).

The singular/plural ambiguity of $i h r^{*}$ is restricted to contexts that offer a structurally accessible singular female and an accessible plural possessor candidate as well, as in (8c), or two or more singular candidates that can be cumulated into a plural possessor and at least one of which is female, as in (8b) and (10). Under both conditions pragmatics undoubtedly will play a major role in the resolution process. It seems plausible, however, that unless there are very good semantic-pragmatic reasons for the opposite, ihr* will preferably be resolved to a singular female possessor candidate if the alternative is a summative plural interpretation. Our resolution test (Sect. 6) also addresses this assumption.

[5] Pilot study on grammaticality judgment

As a pilot study we conducted a rather simple grammaticality judgment experiment with Norwegian students of German.

\section{[5.1] Test design}

\section{Materials}

The test comprised a list of 24 test sentences with possessive pronouns, interspersed with 26 distractors containing different types of determiners. The test items were context-free one-clause sentences containing an occurrence of sein* or $i r^{*}$ as part of a complement DP. The subject being the only antecedent candidate in the sentence, the possessive should be understood as locally bound and under that reading be judged grammatical or ungrammatical depending on whether it matches or mismatches the subject with respect to number and gender. Examples of the relevant variations are given in (16) and (17), distractors are exemplified in (18). There were 12 items with sein*, 6 grammatical and 6 ungrammatical, and 12 items with $i h r, 4$ of each type illustrated in (17), i.e. 8 grammatical and 4 ungrammatical. ${ }^{16}$

[16] It is an interesting question - which we did not pursue - how native speakers of German would judge or react to the 'ungrammatical' items. 
(16) a. Der Opa begleitet seinen Enkel zum Kindergarten. sein* match 'Grandpa escorts his grandson to the kindergarden.' (gender)

b. *Die Studentin findet seinen Platz nicht. sein* mism. 'The (female) student doesn't find his place.' (gender)

c. *Die Berliner sind stolz auf seine Stadt. sein* mism. 'The Berliners are proud of their town.' (number)

(17) a. Katrin hat Diskussionen mit ihren_Kollegen. ihr* match 'Katrin has discussions with her colleagues.' (gender)

b. *Der Nachbar erzählt nie von ihrem Job. ihr* mism. 'The (male) neighbor never talks about her job.' (gender)

c. Alle Kinder sind mit ihren Eltern angekommen. ihr* match 'All (the) children arrived with their parents.' (number)

(18) a. Paul verbringt die meiste Zeit in der Bibliothek. 'Paul spends most of the time (lit: the most time) in the library.'

b. *Kristine bestellt immer die teuerste Gericht. 'Kristine always orders the most expensive food.'

We did not conduct a vocabulary test. However, in the formulation of test items and fillers, an attempt was made to keep both the vocabulary and the type of constructions at an everyday conversational level, i.e. a level one could expect the students to have reached.

Participants

The participants were 41 Norwegian students at the end of their first term of German studies at university level. Their L1 was Norwegian and they largely had the same background concerning German, i.e. German at high school level.

Task

The test sentences were presented in a classroom setting on paper, with the task formulated in German on the top of the page: Determine the grammaticality of the italicized determiners and pronouns in the following examples. The answer alternatives were given in Norwegian - riktig/ feil/ vet ikke ('Ggrammatically] correct/ [grammatically] incorrect/ don't know') - in boxes underneath each sentence. To avoid misunderstandings and prevent disturbing questions, the participants were instructed orally to read the sentence once without dwelling on the example, i.e. to make their judgment without analyzing, and then go on to the next sentence. They were told explicitly not to focus on in- 
flectional endings but to interpret the sentence in the given (empty) context. The time allotted to the whole test was 30 minutes, thus a little more than 30 seconds for each sentence.

\section{[5.2] Hypotheses}

In accordance with the assumptions outlined in Sect. 4 we had the following hypotheses:

H1-1 The grammaticality of sein* is more often judged incorrectly under the (ungrammatical) mismatch than under the (grammatical) match condition.

H1-2 Under the match condition, the grammaticality of $i h r^{*}$ is more often judged incorrectly than the grammaticality of sein*.

H1-3 Under the mismatch condition, the grammaticality of sein* is more often judged incorrectly than the grammaticality of $i h r^{*}$.

H1-1 relates to fact that sein* is neutral with respect to binding but morphophonologically similar to the Norwegian reflexive possessive $s i^{*}$; cf. (ii) in Sect. 4. The similarity is expected to enhance a correct judgment of the match cases, where a reflexive interpretation of $\operatorname{sein}^{*}$ is indeed grammatically licensed, but may conversely prevent the learners from realizing that sein* cannot correctly refer to a non-matching local subject.

The rationale behind H1-2 and H1-3 is that as far as ihr* is concerned, there is no cross-linguistic similarity to trigger comparable - positive or negative effects on the judgment. That is, everything else being equal we would expect the ratio between correct and incorrect judgments to differ less across conditions than with sein*.

\section{[5.3] Results}

We measured the results in terms of what we shall call the error rate, i.e. the frequency (percentage) of positively wrong judgments relative to the total number of judgments that are either correct or wrong, excluding missing and don't-know judgments, i.e. uncertain responses. Under the uncertainty rate we understand the frequency of the latter relative to the total number of judgments, i.e. the number of items of the relevant type multiplied by the number of responding participants. The results are presented in Table 1.

As far as H1-1 is concerned, there were altogether 192 correct, 40 wrong and 14 uncertain judgments for grammatically correct, number-gender-matching $\operatorname{sein}^{*}$, i.e., items of type (16a). This yields an error rate of $17.2 \%$. The uncertainty rate was $5.7 \%$. Under the mismatch condition, i.e. with ungrammatical sein*, the 
error rate was significantly higher $(27.1 \%$ vs. $17.2 \%), \chi^{2}(1, N=461)=5.9, p=.015$. The uncertainty rates did not differ significantly $(6.9 \%$ vs. $5.7 \%), \chi^{2}(1, N=492)=$ $0.14, p=.71$. All in all then, H1-1 may be considered corroborated.

\begin{tabular}{|c|c|c|c|c|c|c|c|c|c|}
\hline \multirow{3}{*}{ Possessive } & \multirow{3}{*}{$\begin{array}{l}\text { Condition } \\
\text { (Item type) }\end{array}$} & \multicolumn{7}{|c|}{ Judgments } & \multirow{3}{*}{$\begin{array}{c}\text { Error } \\
\text { rate }\end{array}$} \\
\hline & & \multirow{2}{*}{$\begin{array}{c}\text { Total } \\
\mathrm{n}\end{array}$} & \multicolumn{2}{|c|}{ Correct } & \multicolumn{2}{|c|}{ Wrong } & \multicolumn{2}{|c|}{ Uncertain } & \\
\hline & & & $\mathrm{n}$ & $\%$ & $\mathrm{n}$ & $\%$ & $\mathrm{n}$ & $\%$ & \\
\hline \multirow[t]{2}{*}{$\operatorname{sein}^{*}$} & Match (16a) & 246 & 192 & 78.0 & 40 & 16.3 & 14 & 5.7 & $17.2 \%$ \\
\hline & Mismatch $(16 b, c)$ & 246 & 167 & 67.9 & 62 & 25.2 & 17 & 6.9 & $27.1 \%$ \\
\hline \multirow{2}{*}{$i h r^{*}$} & Match $(17 a, c)$ & 328 & 228 & 69.5 & 82 & 25.0 & 18 & 5.5 & $26.5 \%$ \\
\hline & Mismatch (17b) & 164 & 83 & 50.6 & 64 & 39.0 & 17 & 10.4 & $43.5 \%$ \\
\hline
\end{tabular}

TABLE1: Results of grammaticality judgment test

With grammatically correct, number-gender-matching $i h r^{*}$, i.e. items of type $(17 \mathrm{a}, \mathrm{c})$, there were 228 correct, 82 wrong and 18 undecided judgments, giving an error rate of $26.5 \%$ and an uncertainty rate of $5.5 \%$. Compared to the error rate for sein* under the match condition, $i h r^{*}$ fared significantly worse $(26.5 \%$ vs. $17.2 \%), \chi^{2}(1, N=542)=5.9, p=.015$, thus weakly corroborating H1-2.

As for the ungrammatical $i h r^{*}$ items of the type illustrated in (17b), the results show a an error rate of $43.5 \%$ and an uncertainty rate of $10.3 \%$. In other words, under the mismatch condition the error rate for ihr* is considerably higher than under the match condition - and significantly higher than for sein* $(43.5 \%$ vs. $27.1 \%), \chi^{2}(1, N=376)=10.2, p=.014$. H1-3, then, is not corroborated.

\section{[5.4] Discussion}

Our results may be summarized as follows:

(i) The error rate is higher for $i h r^{*}$ than for sein* under the match as well as the mismatch condition. This may indicate that as far as grammaticality judgment is concerned, $i h r^{*}$ on the whole represents a more difficult case than sein*.

(ii) For both sein* and $i h r^{*}$ the error rates are higher under mismatch than under match. Evidently, it is easier to correctly judge the grammaticality of a possessive occurring in a locally bound position when the possessive matches than when it does not match its (intended) local binder.

(iii) As far as our unreliable friends sein* and Norwegian $s i^{*}$ are concerned, their similarity may have enhanced correct judgment of 
$\operatorname{sein}^{*}$ (as compared to $i h r^{*}$ ) under the match condition, where the reflexive interpretation inherent to $s i^{*}$ is in fact grammatically licensed for sein* ('positive transfer'). Under the mismatch condition, the reflexive reading of sein* is not grammatically licensed while $s i^{*}$ would still be correct in Norwegian. However, we cannot tell whether or to what degree the poorer result under mismatch is due specifically to interference ('negative transfer') from $s i^{*}$ rather than a generally lower ability to correctly judge ungrammatical possessives or structures in L2; cf. (ii).

(iv) The fact that $i h r^{*}$ seems to present a more difficult case could be ascribed to several factors. First, although the informants were told not to focus on morphological endings, it is impossible to tell in how far their judgments actually were influenced by the latter. Expressions such as ihr Studium, ihr Pensum might appear odd without a morphological ending. Furthermore, the form ihr is homophonous with the singular dative form of the number-ambiguous $3^{\text {rd }}$ person pronoun sie 'she/they'. Thus, the combination of $i h r$ and a neutral noun, as for instance ihr Studium, might seem wrong altogether. In addition, some test persons may have associated $i h r^{*}$ with irreflexive hennes or deres, disregarding the possibility of a reflexive interpretation (cf. Sect. 4).

Some of the uncertainties concerning the judgments might have been resolved by following up the test with an interview. Still, we consider the results to give some indication of the type of problems facing Norwegian learners in relation to L2-German possessives. While there appear to be numerous challenges concerning $i h r^{*}$, the results for sein* are compatible with our assumption of transfer from L1-Norwegian.

\section{[6] Resolution experiment}

\section{[6.1] Preliminaries}

Whereas the previous section was concerned with L1-Norwegian participants' grammaticality judgments on locally bound occurrences of ihr* and sein*, the test presented in this section investigates their ability to identify the possessor under unambiguously local or non-local binding of the possessive (in the somewhat sloppy sense of the term binding; se fn. 5). Our main assumption concerning sein* still encompasses the notion of transfer - or so-called crosslinguistic influence (CLI) - in that we expect the L1-Norwegian participants to 
wrongly understand non-locally bound sein* reflexively, in the sense of locally bound $s i^{*}$, rather than to interpret locally bound sein* as non-locally bound (irreflexive) hans. For the correct/incorrect judgment of $i h r^{*}$ we presented in Sect. 5.4 a list of factors that might interfere; the one of importance to interpretation is the assumed association with the irreflexive Norwegian possessive hennes (singular) or deres (plural) even in cases of local binding. A related matter, suited for comparison with native speakers, is the Norwegian learners' interpretation of $i h r^{*}$ as either singular or (summative) plural.

\section{[6.2] Test design}

\section{Material}

The test material comprises a set of 32 experimental items interspersed with 32 fillers. Each experimental item is a context-free complex sentence consisting of a main clause and a subordinate adverbial clause (with während 'while') in that order; both clause subjects are singular gender-specific proper names but differ in gender; and one of the clauses contains a $3^{\text {rd }}$ person possessive as part of a complement DP. ${ }^{17}$

The experimental items come in eight types, representing every combination of three binary conditions:

(i) Possessive: sein*, demanding a male singular possessor, vs. ihr*, demanding a female singular or a plural possessor;

(ii) MATCH/BINDING: The setup ensures that the possessive either matches or mismatches the subject of its own clause - the local subject - in (singular) gender. If the two match, a locally bound, i.e. reflexive, interpretation of the possessive is warranted (Local Match/Binding), since there is no pre-context; if not, the possessive will match the clause-external subject (Non-local Match/Binding), thus demanding a non-reflexive interpretation - cataphoric (forward-looking) or anaphoric (in the restricted sense of backward-looking, see Sect. 3.1) depending on its position in the sentence; cf. (iii).

(iii) Position: The possessive either occurs in the first, main clause (PossC1) or in the second, subordinate clause (PossC2).

[17] The design is inspired by the offline comprehension experiment described in Pitz et al. (2017: 58-69), which concerned L1-German speakers' comprehension of the L2-Norwegian possessives si* and hans. However, the order of subordinate and main clause is reversed; and the experimental items are context-free, primarily because a pre-context introducing the competing possessor candidates would blur the distinction between anaphoric and cataphoric use of the possessive. 
Examples (19)-(22) illustrate the eight combinations, each of which is represented by four experimental items. Note, though, that the conditions were not manipulated within items (sentence contexts) but varied across the set of 32 individual experimental items.

(19) a.. Jakob legt das Gemüse in seinen Korb, während Siri an der PossC1 Kasse wartet.

'Jakob puts the vegetables in his basket while Siri is waiting at the checkout'

b. Brigitte räumt die Wohnung auf, während Daniel an seiner PossC2 Abhandlung arbeitet.

'Birgitte tidies the apartment while Daniel works on his thesis.'

Non-local Match/Binding

(20) a. Siri legt das Gemüse in seinen Korb, während Jakob an PossC1 der Kasse wartet. (cataphoric) 'Siri puts the vegetables in his basket while Jakob is waiting at the checkout.'

b. Daniel räumt die Wohnung auf, während Brigitte an PossC2 seiner Abhandlung arbeitet.

'Daniel tidies the apartment while Brigitte works on his thesis.'

(21) a. Siri legt das Gemüse in ihren Korb, während Jakob an der PossC1 Kasse wartet.

'Siri puts the vegetables in her basket while Jakob is waiting at the checkout.'

b. Daniel räumt die Wohnung auf, während Brigitte an ihrer PossC2 Abhandlung arbeitet.

'Daniel tidies the apartment while Brigitte works on her thesis.'

$$
\text { Non-local Match/Binding }
$$

(22) a. Jakob legt das Gemüse in ihren Korb, während Siri an

'Jakob puts the vegetables in her basket while Siri is waiting at the checkout.'

b. Brigitte räumt die Wohnung auf, während Daniel an PossC2 ihrer Abhandlung arbeitet. 
'Brigitte tidies the apartment while Daniel works on her thesis.'

Note also that under all conditions, $i h r^{*}$ in principle is ambiguous between a singular (locally or non-locally bound) reading and a summative plural interpretation ('their'), referring to the two subject DPs.

The 32 fillers served to test reading comprehension at a general level and to distract the participants from the possessives. They all consisted of two clauses - mostly a main and a während-clause - with proper name subjects differing in gender; and the majority contained the locally bound (reflexive) pronoun sich or a non-locally bound $3^{\text {rd }}$ person personal pronoun referring to the non-local subject; cf. (23). The rest were of the contrasting type illustrated in (24).

(23) a. Siri füllt eine Thermoskanne mit Tee, während Peter sich ein Käsebrot macht.

'Siri fills a thermos with tea while Peter makes himself a sandwich.'

b. Weil Anna ihm Schokolade geschenkt hatte, brachte Magnus Nüsse vom Supermarkt mit.

'Because Anna gave him chocolate, Magnus brought nuts from the supermarket'

c. Oskar wäscht zwei Äpfel, während Luise ihm ein Lachsbrötchen macht.

'Oscar washes two apples while Luise makes him a salmon sandwich'

Ella ist 48 Jahre alt, während Hans gerade 47 geworden ist.

'Ella is 48 years old while Hans recently turned 47.

With some exceptions among the fillers, the vocabulary and syntactic complexity of the test items were adapted to the proficiency level of the L2participants.

\section{Participants}

31 Norwegian learners of L2-German (L2 group) and a control group of 16 native speakers of German (L1 group) participated in the experiment. As in our pilot study (Sect. 5), the Norwegian participants were students of introductory-level German courses at Norwegian universities at the time of testing; 18 (group L2-a) had had two years' and 13 (group L2-b) three years' teaching of German at high school level. The L1-participants were exchange students from a Germanspeaking country, with an average age of 26 years. The majority of the participants were female. 


\begin{tabular}{cccc}
\hline $\begin{array}{c}\text { Participant } \\
\text { group }\end{array}$ & Proficiency in German & Age \\
range
\end{tabular}

TABLE 2: Participants in the resolution experiment

\section{Procedure}

The test items (experimental items and fillers) were shown on a computer screen to one participiant at a time, being presented one by one in random order. All participants were confronted with all 64 items. For each item, they had to presss a button to indicate that they had finished reading. Having done so, they were prompted to answer a wh-question in German relating to the content of the item. With experimental items they were asked to identify the referent of the possessive pronoun, i.e. the 'possessor' of the entity denoted by the DP containing the possessive. The answer was given by pressing a specific button: $\mathbf{M}$ for the male referent, $\mathbf{F}$ for the female referent and $\mathbf{B}$ ('both') for the (summative) plural referent. For instance, (19a) is followed by (25), the correct response being $\mathrm{M}$. For each participant, the reading time and the reaction time the time taken to submit an answer - were recorded. Only a single answer was permitted per question; in the case of $i r^{*}$, then, the participants had to choose between a female singular and a plural interpretation. In other words: the coreference resolution task presented to the participans involved forced choice interpretation.

Wem gehört der Korb? ('Who owns the basket?')

$$
\text { Press F for Siri Press M for Jakob Press B for Both }
$$

[6.3] Hypotheses and questions

Our central hypotheses concern the possible effects of POSSESSIVE, MATCH/BINDING and LANGUAGE (L2- vs. L1-German) on the resolution of sein* and ihr* in complex sentences of the kind specified in the previous section:

H2-1 On average, the Norwegian learners resolve the possessives correctly less often than the German-speaking control group. 
H2-2 Specifically the Norwegian learners more often resolve the possessives incorrectly under Non-local than under Local Match/Binding, the difference being more substantial for sein* than for $i h r^{*}$.

H2-3 The Norwegian learners resolve sein* to the subject of its own clause (i.e. reflexively) significantly more often than they do with $i h r^{*}$.

We also wanted to see (i) whether Position might have an effect on the two groups' resolution performance, and (ii) whether there might be a general preference for resolving ihr* to the accessible singular female (F button) rather than understanding the possessive as a summative plural (B button).

Throughout, it should be borne in mind that since the items with ihr* in principle allow both a singular and a plural interpretation while there is only one correct answer (the M button) to the sein* items, the chances of answering correctly when choosing randomly are twice as high for ihr* as for sein* items. Accordingly, we would expect the proportion of questions answered correctly to be generally higher for ihr* than for sein*.

In the analysis, a $\chi^{2}$-test was used to test combinations of conditions against each other in $2 \times 2$ contigency tables with one dimension representing the given condition and the other the number of successfully and unsuccessfully answered items. Every condition was tested across the other conditions, with primary focus on POSSESSIVE (sein* vs. ihr*), MATCH/BINDING and LANGUAGE.

[6.4] Results

Overview (H2-1)

All participants responded adequately to all 32 experimental items, yielding a total of 512 responses from the L1 and 992 from the L2 group.

Table 3 (for L1) and Table 4 (for L2) show how the responses are distributed over the three given options - M[ale referent], $\mathrm{F}$ [emale referent] and $\mathrm{B}$ [oth, i.e. the two referents together] - across the different item types (combinations of conditions; see Sect. 6.2). Numbers/ percentages of grammatically licensed ('correct') resolutions are blue, numbers/ percentages of grammatically illicit ('wrong') resolutions in italics and red.

Note that, abstracting from the plural option for ihr*, the condition Local Match/Binding demands a reflexive interpretation of the possessive, whether the latter occurs in the first or second clause of the complex sentence (PossC1 vs. PossC2). With Non-local Match/Binding, on the other hand, the possessive is non-reflexive and cataphoric (PossC1) or anaphoric (PossC2); see Section 6.2. 


\begin{tabular}{|c|c|c|c|c|c|c|c|c|c|}
\hline & & \multicolumn{7}{|c|}{ Resolution/ Response } & \multirow{3}{*}{$\begin{array}{c}\text { Success } \\
\text { rate }\end{array}$} \\
\hline \multicolumn{2}{|r|}{ Condition } & \multicolumn{2}{|c|}{$M$} & \multicolumn{2}{|c|}{$\mathrm{F}$} & \multicolumn{2}{|c|}{ B } & \multirow{2}{*}{$\begin{array}{l}\text { Total } \\
100 \%\end{array}$} & \\
\hline & & $\mathrm{n}$ & $\%$ & $\mathrm{n}$ & $\%$ & $\mathrm{n}$ & $\%$ & & \\
\hline \multirow{7}{*}{ 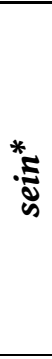 } & Local & 115 & $90 \%$ & 4 & $3 \%$ & 9 & $7 \%$ & 128 & $90 \%$ \\
\hline & PossC 1 & 57 & $89 \%$ & 1 & $2 \%$ & 6 & $9 \%$ & 64 & $89 \%$ \\
\hline & PossC2 & 58 & $91 \%$ & 3 & $5 \%$ & 3 & $5 \%$ & 64 & $91 \%$ \\
\hline & Non-Loc. & 112 & $88 \%$ & 13 & $10 \%$ & 3 & $2 \%$ & 128 & $88 \%$ \\
\hline & PossC1 & 51 & $80 \%$ & 10 & $5 \%$ & 3 & $16 \%$ & 64 & $80 \%$ \\
\hline & PossC2 & 61 & $95 \%$ & 3 & $5 \%$ & 0 & $0 \%$ & 64 & $95 \%$ \\
\hline & Total & 227 & $89 \%$ & 17 & $7 \%$ & 12 & $5 \%$ & 256 & $89 \%$ \\
\hline \multirow{7}{*}{$\frac{*}{5}$} & Local & 2 & $2 \%$ & 121 & $95 \%$ & 5 & $4 \%$ & 128 & $99 \%$ \\
\hline & PossC1 & 0 & $0 \%$ & 60 & $94 \%$ & 4 & $6 \%$ & 64 & $100 \%$ \\
\hline & PossC2 & 2 & $3 \%$ & 61 & $95 \%$ & 1 & $2 \%$ & 64 & $97 \%$ \\
\hline & Non-loc. & 4 & $3 \%$ & 88 & $69 \%$ & 36 & $28 \%$ & 128 & $97 \%$ \\
\hline & PossC 1 & 3 & $5 \%$ & 35 & $55 \%$ & 26 & $41 \%$ & 64 & $95 \%$ \\
\hline & PossC2 & 1 & $2 \%$ & 53 & $83 \%$ & 10 & $16 \%$ & 64 & $98 \%$ \\
\hline & Total & 6 & $2 \%$ & 209 & $82 \%$ & 41 & $16 \%$ & 256 & $98 \%$ \\
\hline & oss Total & 233 & $45 \%$ & 226 & $44 \%$ & 53 & $10 \%$ & 512 & $93 \%$ \\
\hline
\end{tabular}

TABLE 3: Overview of L1 resolution results. Local and Non-loc. short for Local Match/Binding and Non-local Match/Binding, respectively.

The two tables also show the success rate (henceforth also: $S R$ ), i.e. the number of correct responses as percentage of the total number of responses under the given condition. Note that the success rate is based on M-responses in relation to $\operatorname{sein}^{*}$ but on the sum of F- and B-responses in relation to ihr.

With an overall SR of $78 \%$, (Table 4, bottom right), the L2-learners evidently were less successful in resolving the possessive correctly than was the L1control group (general SR 98\%, Tab. 3, bottom right). A $\chi^{2}$-test showed the difference to be significant: $\chi^{2}(1, N=1504)=61.6, p<.001$. This finding is in accordance with hypothesis H2-1 (Sect. 6.3) 


\begin{tabular}{|c|c|c|c|c|c|c|c|c|c|}
\hline & \multirow{3}{*}{ Condition } & \multicolumn{7}{|c|}{ Resolution/ Response } & \multirow{3}{*}{$\begin{array}{c}\text { Success } \\
\text { rate }\end{array}$} \\
\hline & & \multicolumn{2}{|c|}{$\mathrm{M}$} & \multicolumn{2}{|c|}{$\mathrm{F}$} & \multicolumn{2}{|c|}{ B } & \multirow{2}{*}{$\begin{array}{c}\text { Total } \\
(100 \%)\end{array}$} & \\
\hline & & $\mathrm{n}$ & $\%$ & $\mathrm{n}$ & $\%$ & $\mathrm{n}$ & $\%$ & & \\
\hline \multirow{7}{*}{$\stackrel{*}{.5}$} & Local & 223 & $90 \%$ & 10 & $4 \%$ & 15 & $6 \%$ & 248 & $90 \%$ \\
\hline & PossC1 & 109 & $88 \%$ & 7 & $6 \%$ & 8 & $6 \%$ & 124 & $88 \%$ \\
\hline & PossC2 & 114 & $92 \%$ & 3 & $2 \%$ & 7 & $6 \%$ & 124 & $92 \%$ \\
\hline & Non-loc. & 105 & $42 \%$ & 125 & $50 \%$ & 18 & $7 \%$ & 248 & $42 \%$ \\
\hline & PossC1 & 50 & $40 \%$ & 61 & $49 \%$ & 13 & $10 \%$ & 124 & $40 \%$ \\
\hline & PossC2 & 55 & $44 \%$ & 64 & $44 \%$ & 5 & $4 \%$ & 124 & $44 \%$ \\
\hline & Total & 328 & $66 \%$ & 135 & $27 \%$ & 33 & $7 \%$ & 496 & $66 \%$ \\
\hline \multirow{7}{*}{$\stackrel{*}{*}$} & Local & 13 & $5 \%$ & 162 & $65 \%$ & 73 & $29 \%$ & 248 & $95 \%$ \\
\hline & PossC1 & 7 & $6 \%$ & 81 & $65 \%$ & 36 & $29 \%$ & 124 & $94 \%$ \\
\hline & PossC2 & 6 & $5 \%$ & 81 & $65 \%$ & 37 & $30 \%$ & 124 & $95 \%$ \\
\hline & Non-loc. & 50 & $20 \%$ & 91 & $37 \%$ & 107 & $43 \%$ & 248 & $80 \%$ \\
\hline & PossC1 & 29 & $23 \%$ & 28 & $23 \%$ & 67 & $54 \%$ & 124 & $77 \%$ \\
\hline & PossC 2 & 21 & $17 \%$ & 63 & $51 \%$ & 40 & $32 \%$ & 124 & $83 \%$ \\
\hline & Total & 63 & $13 \%$ & 253 & $51 \%$ & 180 & $36 \%$ & 496 & $87 \%$ \\
\hline & Poss Total & 391 & $39 \%$ & 388 & $39 \%$ & 213 & $21 \%$ & 992 & $78 \%$ \\
\hline
\end{tabular}

TABLE 4: Overview of L2 resolution results; Local and Non-loc. short for Local Match/Binding and Non-local Match/Binding, respectively

Sein* versus ihr* and effects of MATCH/BINDING (H2-2 and H2-3)

As seen in Table 4 and, more easily, in Table 5 (bottom row), the L2-group performed significantly better with $i h r^{*}$ (SR 87\%) than with sein* (SR 66\%).

\begin{tabular}{|c|c|c|c|c|c|c|c|}
\hline & \multirow{3}{*}{ Condition } & \multicolumn{6}{|c|}{ Success rate } \\
\hline & & \multicolumn{2}{|c|}{$\operatorname{sein}^{*}$} & \multicolumn{2}{|c|}{$i h r^{*}$} & \multicolumn{2}{|c|}{ Total } \\
\hline & & L2 & L1 & L2 & L1 & L2 & $\mathrm{L} 1$ \\
\hline 1 & Local Match/Binding & $90 \%$ & $90 \%$ & 95\% & $\mathbf{9 8 \%}$ & $92 \%$ & 94\% \\
\hline $1 \mathrm{a}$ & PossC1 & $88 \%$ & $89 \%$ & $94 \%$ & $98 \%$ & $91 \%$ & $95 \%$ \\
\hline $1 b$ & PossC2 & $92 \%$ & $91 \%$ & $95 \%$ & $100 \%$ & $94 \%$ & $94 \%$ \\
\hline 2 & Non-Local Match/Binding & $42 \%$ & $88 \%$ & $80 \%$ & $97 \%$ & $61 \%$ & $92 \%$ \\
\hline $2 a$ & PossC1 (cataphoric) & $40 \%$ & $80 \%$ & $77 \%$ & $95 \%$ & $58 \%$ & $88 \%$ \\
\hline $2 b$ & PossC2 (anaphoric) & $44 \%$ & $95 \%$ & $83 \%$ & $97 \%$ & $64 \%$ & $97 \%$ \\
\hline 3 & Total & $66 \%$ & $89 \%$ & $87 \%$ & $\mathbf{9 8 \%}$ & $77 \%$ & $93 \%$ \\
\hline
\end{tabular}

TABLE 5: L2 (dark red) vs. L1 success rates for sein* and ihr* 
The difference between the two success rates is substantial $\left(\chi^{2}(1, N=992)=61.0\right.$, $p<.001$ ), in contrast to the weaker but still significant trend observed in the L1group, where the success rates were $98 \%\left(i h r^{*}\right)$ and $89 \%\left(\right.$ sein $\left.^{*}\right)$, respectively $\left(\chi^{2}(1, N=512)=14.8, p<.001\right)$; Table 5 , bottom.

Table 5 (rows 1 vs. 2) also shows that the Norwegian learners master possessive resolution better under Local Match/Binding, as in (26), than under Nonlocal Match/Binding, as in (27). The difference is highly significant for sein* (SR $90 \%$ vs. $\left.42 \%, \chi^{2}(1, N=496)=123.2, p<.001\right)$. For $i h r^{*}$, the effect is less pronounced (SR 95\% vs. $80 \%)$ but still significant $\left(\chi^{2}(1, N=496)=23.6, p<.001\right)$. The findings are in accordance with $\mathrm{H} 2-2$, showing a significant interaction between POSSESSIVE and MATCH/BINDING.

(26) a. Brigitte wartet an der Kasse, während Daniel Gemüse in seinen Korb legt.

'Brigitte is waiting at the checkout while Daniel puts vegetables in his basket.'

b. Daniel wartet an der Kasse, während Brigitte Gemüse in ihren Korb legt.

(27) a. Daniel wartet an der Kasse, während Brigitte Gemüse in seinen Korb legt.

b. Brigitte wartet an der Kasse, während Daniel Gemüse in ihren Korb legt.

Under Local Match/Binding, the Norwegian comprehenders in fact perform native-like, achieving a success rate of $90 \%$ with sein* and $95 \%$ with $i h r^{*}$ (Tab.5, row 1). Under Non-local Match/Binding (Tab. 5, row 2), their SR for ihr* is still quite high - with $80 \%$ almost twice as high as for $\operatorname{sein}^{*}(42 \%)$ - but significantly lower than the control group's $97 \%\left(\chi^{2}(1, N=256)=18.6, p<.001\right)$.

By contrast, MATCH/BINDING (Local vs. Non-local) had no significant effect on the L1-comprehenders' performance for either $\operatorname{sein}^{*}$ (SR 90\% vs. $88 \%, \chi^{2}(1, N=$ $256)=0.16, p=0.69$ ) or $i h r^{*}$ (SR 98\% vs. 97\%, Fischer's Exact test $p=0.68$ ). That is, the interaction between POSSESSIVE and MATCH/BINDING is conditioned by LANGUAGE as predicted by $\mathrm{H} 2-2$.

Note, however, that while the L1-participants with very few exceptions resolve $i h r^{*}$ in accordance with the rules of German grammar, whether the possessive is locally bound or not, their $89 \%$ success rate for sein* deviates significantly from the $100 \%$ one would expect ( $\mathrm{p}<.001$ according to Fischer's Exact test). It is difficult to say what may have caused the various wrong answers apart from lack of attention (fatigue) or a preference for top-down reading 
based on pragmatic expectations rather than linguistic form. ${ }^{18}$ Notably, though, it is the non-local cataphoric condition that causes most problems, exhibiting a success rate of only $80 \%$; cf. Table 5 , row $2 \mathrm{~b}$. We return to the cataphoricity issue below and in Section 5.5.

H2-3 predicts that the Norwegian learners - rightly or wrongly - understand sein* reflexively, i.e. as referring to the local subject, significantly more often than they do with $i h r^{*}$ (Sect. 6.3). Under our experimental set-up (see Sect. 6.2) a reflexive (i.e. local) interpretation is warranted for half of the experimental items: the 16 items showing Local Match/Binding. A reflexive interpretation of sein* amounts to correctly responding with M (Daniel) in cases like (26a) (Local Match/Binding) and incorrectly responding with $\mathrm{F}$ (Brigitte) in cases like (27a) (Non-local Match/Binding); and the other way around for ihr*, i.e. choosing F (Brigitte) under Local Match/Binding (26b) and M (Daniel) under Non-local Match/Binding (27b).

The data presented in Table 4 above show that $90 \%(n=223)$ of the 248 L2resolutions of sein* under Local Match/Binding were correctly reflexive/local. Of the 248 L2-resolutions of sein* under Non-local Match/Binding, 50\% $(n=125)$ were incorrectly reflexive/local. The corresponding figures for $i h r^{*}$ are $65 \%(\mathrm{n}=$ $162)$ and $20 \%(\mathrm{n}=50)$, respectively. Under both conditions, the reflexivity difference between the two possessives is significant: $\chi^{2}(1, N=478)=106.6, p<.001$ and $\chi^{2}(1, N=496)=12.4, p<.001$, respectively. (Note, incidentally, that the L1participants also under Non-local Match/Binding strongly prefer the reflexive (female) singular to the non-reflexive plural interpretation; see below and Tab. 3 above).

Obviously, the lower frequency of reflexive/local L2-resolutions of ihr* may have to do with the fact that the summative plural interpretation is a licensed alternative to the female singular. Thus if we leave the $\mathrm{B}$ responses out of the counting for both possessives, their reflexivity rates (sein* $93 \%$, ihr* $96 \%)$ do not differ significantly under Local Match/Binding, where the reflexive/local resolution is correct. Under Non-Local Match/Binding, however, ihr* still exhibits a significantly lower rate of (incorrectly) reflexive/local resolutions than sein*: $35 \%(50 / 141)$ vs. $54 \%(125 / 230), \chi^{2}(1, N=371)=11.8, p<.001$. Altogether, then, we may consider $\mathrm{H} 2-3$ corroborated.

Effects of POSITION and the singular-plural ambiguity of ihr*

In our experimental items, the possessive either occurs in the second clause (PossC2), as in (26)-(27) above, or in the first clause (PossC1), as in (28)-(29) be-

[18] L1 speakers may also have been unfamiliar with a proper name like Siri (female in Norwegian). 
low. Under Non-local Match/Binding, PossC1 and PossC2 amount to cataphoric (29) and anaphoric (27) use of the possessive, respectively.

(28) a. Jakob legt das Gemüse in seinen Korb, während Siri an der Kasse wartet.

'Jakob puts the vegetables in his basket while Siri is waiting at the checkout.'

b. Siri legt das Gemüse in ihren Korb, während Jakob an der Kasse wartet.

(29) a. Siri legt das Gemüse in seinen Korb, während Jakob an der Kasse wartet.

b. Jakob legt das Gemüse in ihren Korb, während Siri an der Kasse wartet.

As shown in Table 5 above, the success rates in both the L2- and the L1-group are somewhat higher with PossC2 than with PossC1 under Local Match/Binding (rows 1a vs. 1b) than under Non-local Match/Binding (rows 2a vs. 2b). On the whole, however, the differences are too small to be significant. The greatest numerical contrast is found for L1 with respect to cataphoric vs. anaphoric sein* (SR 80\% vs. 95\%), Fischer's Exact test: $p=.14$.

Turning to the question of how the L1 and L2 participants performed with respect to the singular-plural ambiguity of $i h r^{*}$ (Sect. 4), Table 6 shows the distribution of (female) singular (F) and summative plural (B) resolutions in relation to the total number of grammatically licensed (F or B) resolutions of $i h r^{*}$.

\begin{tabular}{|c|c|c|c|c|c|c|c|c|c|c|c|}
\hline & & \multicolumn{10}{|c|}{ Correct resolutions/ responses for $i h r^{*}$} \\
\hline & & & & $\mathbf{L}$ & & & & & $\mathrm{L} 2$ & & \\
\hline \multicolumn{2}{|c|}{ Condition } & \multicolumn{2}{|c|}{$\mathrm{F}$} & \multicolumn{2}{|c|}{$\mathrm{B}$} & \multirow{2}{*}{$\begin{array}{c}F+B \\
(100 \%)\end{array}$} & \multicolumn{2}{|c|}{$\mathrm{F}$} & \multicolumn{2}{|c|}{ B } & \multirow{2}{*}{$\begin{array}{c}F+B \\
(100 \%)\end{array}$} \\
\hline & & $\mathrm{n}$ & $\%$ & $\mathrm{n}$ & $\%$ & & $\mathrm{n}$ & $\%$ & $\mathrm{n}$ & $\%$ & \\
\hline 1 & Local & 121 & $96 \%$ & 5 & $4 \%$ & 126 & 162 & $69 \%$ & 73 & $31 \%$ & 235 \\
\hline $1 \mathrm{a}$ & PossC1 & 60 & $94 \%$ & 4 & $6 \%$ & 64 & 81 & $69 \%$ & 36 & $31 \%$ & 117 \\
\hline $1 b$ & PossC2 & 61 & $98 \%$ & 1 & $2 \%$ & 62 & 81 & $69 \%$ & 37 & $31 \%$ & 118 \\
\hline 2 & Non-loc. & 88 & $71 \%$ & 36 & $29 \%$ & 124 & 91 & $46 \%$ & 107 & $54 \%$ & 198 \\
\hline $2 a$ & Cataphoric & 35 & $57 \%$ & 26 & $43 \%$ & 61 & 28 & $29 \%$ & 67 & $71 \%$ & 95 \\
\hline \multirow[t]{2}{*}{$2 b$} & Anaphoric & 53 & $84 \%$ & 10 & $6 \%$ & 63 & 63 & $61 \%$ & 40 & $39 \%$ & 103 \\
\hline & Total & 209 & $84 \%$ & 41 & $16 \%$ & 250 & 253 & $58 \%$ & 180 & $42 \%$ & 433 \\
\hline
\end{tabular}

TABLE 6: L1 vs. L2 distribution of fem. sing. (F) versus summative plural (B) resolutions of $i h r^{*}$ : F responses as percentage of correct (F or B) resolutions of $i h r^{*}$. Local: Local Match/Binding, Non-loc.: Non-local Match/Binding 
As can be seen, the L1-participants clearly prefer the F response unless $i h r^{*}$ is used cataphorically. By contrast, the L2-participants show a only moderate bias towards the female singular resolution $\left(69 \%, \chi^{2}(1, N=471)=16.7, p<.001\right)$ under Local Match/Binding, where it amounts to a reflexive interpretation. Under the anaphoric condition, where the matching female singular candidate occurs in the preceding clause, the $61 \%$ bias towards that candidate is insignificant because of the lower number of correct $(F+B)$ responses $\left(\chi^{2}(1, N=207)=2.2, p=\right.$ .14). Under the cataphoric condition, however, only $29 \%$ of the resolutions fell on the female singular candidate; that is, here the preference is significantly inverted to the summative plural option $\left(71 \%, \chi^{2}(1, N=191)=7.6, p<.01\right)$.

In short: with the exception of the cataphoric condition, where the possessive precedes the only matching singular candidate, the structure of our experimental items generally favours resolving $i h r^{*}$ to the only accessible female singular candidate rather than to the sum of both candidates, in particular among the L1-participants.

From the results presented in tables 5 and 6 we conclude that Position whether the possessive occurs in the first or the second clause of the experimental structure - has an effect only in combination with Non-local Match/Binding.

\section{Effects of L2-proficiency}

As would be expected, the L2-participants with three years' German at highschool level ( $\mathrm{L} 2-\mathrm{b}, \mathrm{n}=18$ ) performed better in most relevant respects than the group with only two years' high-school German (L2-a, $\mathrm{n}=13$ ). Specifically, their SR for sein* was significantly higher ( $72 \%$ vs. $\left.62 \%, \chi^{2}(1, N=496)=5.3, p=0.02\right)$, while the difference was insignificant with $i h r^{*}\left(90 \%\right.$ vs. $85 \%, \chi^{2}(1, N=496)=1.8$, $p=0.18$ ); cf. Table 7. The contrast between the two levels is most marked for sein* under Non-local Match/Binding, where L2-a responded correctly with a frequency of only $35 \%$ against $53 \%$ in L2-b $\left(\chi^{2}(1, N=248)=7.4, p<0.01\right)$.

\begin{tabular}{ccccccc}
\hline \multirow{2}{*}{ Condition } & \multicolumn{5}{c}{ Success rate } \\
& \multicolumn{2}{c}{ L2-a } & & L2-b \\
& sein* $^{*}$ & ihr* & Total & sein* $^{*}$ & ihr* & Total \\
\hline Local Match/Binding & $89 \%$ & $94 \%$ & $92 \%$ & $91 \%$ & $95 \%$ & $93 \%$ \\
Non-local Match/Binding & $35 \%$ & $76 \%$ & $56 \%$ & $53 \%$ & $85 \%$ & $69 \%$ \\
\hline Total & $\mathbf{6 2 \%}$ & $\mathbf{8 5 \%}$ & $\mathbf{7 4 \%}$ & $\mathbf{7 2 \%}$ & $\mathbf{9 0 \%}$ & $\mathbf{8 1 \%}$ \\
\hline
\end{tabular}

TABLE 7: L2-a vs. L2-b success rates for sein* and ihr* across MATCH/BINDING 
It may be added that the plural interpretation of $i h r^{*}$ (B response), which may indicate uncertainty, also has a higher relative frequency among the L2-a participants than in the L2-b group, in particular under the cataphoric condition.

\section{[6.5] Summary and discussion}

First, our three central hypotheses (Sect. 6.3) were all supported: In accordance with H2-1, the Norwegian learners of L2-German altogether were less successful in resolving the possessives correctly than the L1-German control group. However, their performance varied considerably across conditions. Like the L1group, they achieved higher success rates with ihr* than with sein* across conditions - not surprisingly in view of the fact that the ihr* items have two correct resolution options against only one with sein*. Different from the L1-group, however, they had significantly lower success rates when the possessive referred to the subject of the preceding or following clause (Non-local Match/Binding) than when a reflexive interpretation was licensed (Local Match/Binding); and in accordance with H2-2, the contrast was significantly more marked for sein* than for ihr*; see Table 5. More specifically: Under Nonlocal Match/Binding, sein* showed a significantly higher rate of (incorrectly) reflexive/local resolutions than $i h r^{*}$ (see Sect. 6.4 for details). Thus, H2-3 too is supported.

Second, the L1-group preferred the female singular to the summative plural interpretation of $i h r^{*}$, the preference being very pronounced under Local Match/Binding, somewhat less so under the anaphoric and insignificant under the cataphoric condition (Table 6). Singular was preferred by the L2-group, too, but the bias was less marked and under the cataphoric condition the plural resolution prevailed (Table 6). Now, since plural is a generally acceptable interpretation of $i h r^{*}$ in our experimental items, it may be chosen so as to avoid deciding between the local and the non-local singular candidate. This would explain why it has a higher frequency in the L2 than in the L1 responses.

Third, Position had a substantial effect on the resolution only under Nonlocal Match/Binding, i.e. when the possessive according to the rules of German grammar cannot be understood reflexively: In both the L2- and the L1-group, the cataphoric structure triggered more plural resolutions of $i h r^{*}$ than the anaphoric structure (Tab. 6); and the L1-group showed a lower success rate with cataphoric than with anaphoric sein* (Tab. 5). In view of the possible fallback function of the summative plural, these findings indicate that our cataphoric condition represents a resolution challenge (even) to native speakers of German. ${ }^{19}$ The L2-participants, too, perform worse with cataphoric than with ana-

[19] In fact, some L1-participants commented on cataphoric (sein*-) items as being 'incorrect'. 
phoric sein* but their success rate in the latter case is already very low (Tab. 5). ${ }^{20}$

Note here that the experimental items all consisted of a main and a subordinate clause in that order, with the possessive occurring in either the first or the second clause (Sect. 6.2). Consequently, our anaphoric and cataphoric conditions differ in two respects: The anaphoric possessive e.g. in (30) refers back from a subordinated to a matrix clause DP while the cataphoric possessive in (31) refers forward from the matrix to the subordinate clause. And as mentioned in Section 3.1, cataphoricity of that kind is more severely constrained than forward dependencies from a subordinate clause to its matrix clause. On this background, the abovementioned results may not be too surprising.

(30) a. Daniel wartet an der Kasse, während Brigitte Gemüse in seinen Korb legt.

b. Brigitte wartet an der Kasse, während Daniel Gemüse in ihren Korb legt

(31) a. Brigitte legt Gemüse in seinen Korb, während Daniel an der Kasse wartet.

b. Daniel legt Gemüse in ihren Korb, während Brigitte an der Kasse wartet.

Accordingly, one would expect a more successful performance when the cataphoric dependency goes from a preposed subordinate clause to its matrix clause, i.e. under conditions that license cataphoric use of ordinary pronouns (see Sect. 3.1). A natural follow-up to our resolution test, then, would be based on experimental items that differ from the present ones with respect to the order of subordinate and main clause but otherwise follow the same pattern of variation (see Sect. 6.2), i.e. pairs like (32) and (33) for anaphoric vs. cataphoric use of the possessive. ${ }^{21}$

(32) a. Während Daniel an der Kasse wartet, legt Brigitte Gemüse in seinen Korb.

b. Während Brigitte an der Kasse wartet, legt Daniel Gemüse in ihren Korb.

[20] Drummer \& Felser (2018: 98) assume that "[r]esolving cataphoric dependencies might be particularly challenging for non-native [...] speakers because they may have more difficulties anticipating upcoming referents compared to native (L1) speakers'. Evidently, nothing in our L2-group's performance under the cataphoric condition contradicts that assumption.

[21] We originally intended to include these variations in our experiment but for practical reasons had to give up the idea. 
(33) a. Während Brigitte Gemüse in seinen Korb legt, wartet Daniel an der Kasse.

b. Während Daniel Gemüse in ihren Korb legt, wartet Brigitte an der Kasse.

Fourth, concerning L2-PROFICIENCY/LEVEL, we found a significant difference in success rates between L2-learners with 2 years of high-school German (group L2-a) and those with 3 years' training (group L2-b). This indicates the fruitfulness of formal training both with regards to mastery of possessive systems that are in very nuanced ways different from one's L1 and with regards to handling the negative cognacy effects of false friends.

\section{[7] Conclusion and outlook}

The primary objective of our enterprise was to find out how L1-Norwegian learners of L2-German at a low or moderate level of profiency (see Sect. 5.1 and 6.2) cope with the $3^{\text {rd }}$ person possessives sein* and $i h r^{*}$ in comprehension, given the lexical divergence holding between the two binding-neutral German possessives on the one hand and their respective binding-sensitive counterparts in Norwegian on the other hand and, in particular, the morpho-phonological similarity between sein* and the Norwegian reflexive possessive si* $^{*}$ (see Sections 1 and 3).

As far as sein* is concerned, our results seem to corroborate the assumption that the Norwegian L2-learners due to the sein*/si* similarity are more biased towards a reflexive interpretation than warranted by the general preference for locality that has been observed in prior research on pronoun resolution (see Sect. 3.1): While our non-native comprehenders by and large resolved unambiguously reflexive, i.e. locally bound occurrences of $\operatorname{sein}^{*}$ correctly, almost half of their resolutions of anaphoric or cataphoric sein* were erroneously reflexive; in comparison, the German-speaking control group did not have serious resolution problems under either condition (Sect. 6.4; Tables 3, 4 and 5). Also, the (Norwegian) participants in the grammaticality judgment test had a higher error rate when sein* did not than when it did match the subject of its local clause, i.e. its intended local binder (see 5.3-4). Being unspecified for possessor number and gender, the Norwegian reflexive possessive $s i^{*}$ would be grammatically licensed not only when sein* matches but also when it does not match the subject of its local clause in gender, i.e. under the conditions where our L2groups significantly often incorrectly chose a reflexive interpretation or erroneously judged sentences containing a mismatching sein* to be correct. It seems reasonable, then, to ascribe the non-native resolution failures and misjudg- 
ments of $\operatorname{sein}^{*}$ to interference from the unreliable possessive L1-friend $s i^{*}$ rather than to a general preference for local binding. ${ }^{22}$

In line with this explanation, the L1-Norwegian comprehension of L2German $i h r^{*}$ offers quite a different picture: Under conditions licensing a reflexive (female singular) interpretation of $i r^{*}$, our L2-comprehenders showed only a modest (65\%) preference for that option - in contrast to the L1-group; and when the local subject did not match the possessive, their rate of (erroneous) reflexive resolutions was considerably lower for ihr* than for sein* even when we disregard the summative plural alternative (Sect. 6.4, Table 4). In addition, the L2-learners generally had more difficulties judging the grammaticality of $i h r^{*}$ correctly than they had with sein* (Sect. 5.3-4). Altogether these findings may indicate that our L2-learners, as suggested in Section 4, tend to lexically associate $i h r^{*}$ with the irreflexive Norwegian possessives hennes 'her' and deres 'their' rather than with the reflexive $s i^{*}$ but that corresponding interference effects on L2-comprehension to a certain degree are levelled out by a general preference for local resolutions - and the context-dependent possibility of a (summative) plural interpretation.

The more general lesson to be drawn from our observations could be that L1/L2-specific relations of divergence and morpho-phonological similarity at the lexical level, at least at non-advanced stages of L2-learning, might play a more important role in non-native resolution of pronouns than has hitherto been acknowledged.

It might be objected that our study for various reasons does not allow any far-reaching conclusions. The number of experimental items is rather restricted in both experiments; some of the items in the resolution experiment are pragmatically biased towards one or the other licensed interpretation; the number of L1-participants is too small; and the experimental procedures may not have been optimal. Still, we find the results interesting enough to warrant follow-up studies in different directions, in part along the lines suggested in Section 6.5 but also - and perhaps most importantly - investigations into L1Norwegian learners' online processing of L2-German possessives compared to ordinary $3^{\text {rd }}$ person pronouns (cf. Sect. 3.2 and Pitz et al. 2017: 58-69) and their resolution preferences under locality-ambiguous conditions, where the referential issue cannot be settled by grammatical cues (cf. Sect. 4).

[22] Note here that the clause subjects in our comprehension experiments were gender-specific proper nouns, making insufficient command of grammatical gender or agreement rules in German a less plausible explanation. 


\section{REFERENCES}

Antón-Méndez, Inés. 2011. Whose? L2-English speakers' possessive pronoun gender errors. Bilingualism: Language and Cognition 14(3). 318-331.

Arnold, Jennifer E. 2010. How speakers refer: the role of accessibility. Language and Linguistics Compass 4/4.187-203.

Badecker, William \& Kathlein Straub. 2002. The processing role of structural constraints on interpretation of pronouns and anaphors. Journal of Experimental Psychology: Learning, Memory, and Cognition 28(4). 748-769.

Bader, Markus \& Yvonne Portele. 2019. The Interpretation of German Personal Pronouns and d-pronouns. Zeitschrift für Sprachwissenschaft 38. 155-190.

Baron, Irène, Michael Herslund \& Finn Sørensen (eds.). 2001. Dimensions of possession. Amsterdam: Benjamins.

Baumann, Peter, Lars Konieczny \& Barbara Hemforth. 2014. Conversational implicatures in anaphora resolution: Alternative constructions and referring expressions. In Barbara Hemforth, Barbara Mertins \& Cathrine FabriciusHansen (eds.), Psycholinguistic approaches to meaning and understanding across languages, 197-212. Berlin: Springer.

Bie-Lorentzen, Sjur. 2012. Possessiva als Lernproblem - Norwegisch-Deutsch/ Deutsch-Norwegisch. Master thesis. Oslo: University of Oslo.

Bosch, Peter, Graham Katz \& Carla Umbach. 2007. The non-subject bias of German. In Monika Schwarz-Friesel, Manfred Consten \& Marelle Knees (eds.), Anaphors in Text: Cognitive, formal and applied approaches to anaphoric reference 86, 145-164. Amsterdam: Benjamins.

Chomsky, Noam. 1981. Lectures of Government and Binding. Dordrecht: Foris.

Chow, Wing-Yee, Shevaun Lewis \& Colin Phillips. 2014. Immediate sensitivity to structural constraints in pronoun resolution. Frontiers in Psychology 5. https://doi.org/10.3389/fpsyg.2014.00630.

Clahsen, Harald \& Claudia Felser. 2006a. How native-like is non-native language processing?. Trends in cognitive sciences 10(12). 564-570.

Clahsen, Harald \& Claudia Felser. 2006b. Grammatical processing in language learners. Applied Psycholinguistics 27. 3-42.

Colonna, Saveria, Sarah Schimke \& Barbara Hemforth. 2014. Information structure and pronoun resolution in German and French: Evidence from the Vis- 
ual-World Paradigm. In Barbara Hemforth, Barbara Mertins \& Cathrine Fabricius-Hansen (eds.), Psycholinguistic Approaches to Meaning and Understanding across Languages, 175-196. Berlin: Springer.

Cunnings, Ian \& Claudia Felser. 2013. The role of working memory in the processing of reflexives. Language and Cognitive Processes 28. 188-219.

Drummer, Janna-Deborah \& Claudia Felser. 2018. Cataphoric pronoun resolution in native and non-native sentence comprehension. Journal of Memory and Language 101. 97-113.

Fabricius-Hansen, Cathrine, Hans Petter Helland, \& Anneliese Pitz. 2017. An L2 perspective on possessives: Contrasts and their possible consequences. Oslo Studies in Language (OSLa) 9(2). 3-39.

Felser, Claudia. 2019. Structure-sensitive constraints in non-native sentence processing. Journal of the European Second Language Association 3(1). 12-22.

Felser, Claudia \& Ian Cunnings. 2012. Processing reflexives in a second language: The timing of structural and discourse-level constraints. Applied Psycholinguistics 33(3). 571-603.

Foucart, Alice, Mikel Santesteban, Holly P. Branigan \& Martin J. Pickering. 2011. The effect of L1 syntax on the agreement of L2 possessive structures: Evidence from eye-tracking. Unpublished poster presented at the 17th Meeting of the European Society for Cognitive Psychology (ESCOP). San Sebastian, Spain.

Fox, Dieter. 1998. Locality in variable binding. In Pilar Barbosa, Danny Fox, Paul Hagstrom, Martha McGinnis \& David Pesetsky (eds.), Is the Best Good Enough? Optimality and Competition in Syntax, 129-155. Cambridge, MA: MIT Press.

Garnham, Alan. 2000. Mental Models and the Interpretation of Anaphora. $1^{\text {st }}$ ed. London: Psychology Press.

Garrod, Simon. 1998. Resolving pronouns and other anaphoric devices. In Charles Clifton Jr., Lyn Frazier \& Keith Rayner (eds.), Perspectives on Sentence Processing, 339-359. Englewood, NJ: Erlbaum.

Garrod, Simon \& Melody Terras. 2000. The contribution of lexical and situational knowledge to resolving discourse roles: Bonding and resolution. Journal of Memory and Language 42.526-544.

Gast, Volker \& Florian Haas. 2008. On reciprocal and reflexive uses of anaphors in German and other European languages. In Ekkehard König \& Volker Gast 
(eds.), Reciprocals and Reflexives: Theoretical and Typological Explorations, 307346. Berlin: De Gruyter.

Geurts, Bart. 2011. Accessibility and anaphora. In Klaus von Heusinger, Claudia Maienborn \& Paul Portner (eds.), Semantics (HSK 33.2), 1988-2011. Berlin: De Gruyter.

Gompel, Roger P.G. van \& Simon P. Liversedge. 2003. The influence of morphological information on cataphoric pronoun assignment. Journal of Experimental Psychology: Learning, Memory, and Cognition 29. 128-139

Gunkel, Lutz, Adriano Murelli, Susan Schlotthauer, Bernt Wiese \& Gisela Zifonun (eds.) 2017. Grammatik des Deutschen im europäischen Vergleich: das Nominal. Berlin: De Gruyter.

Heim, Irene \& Angelika Kratzer. Semantics of Generative Grammar. Malden, MA: Blackwell.

Helland, Hans Petter. 2017. An empirical L2 perspective on possessives: French/Norwegian. Oslo Studies in Language (OSLa) 9(2). 75-104.

Jarvis, Scott. 2009. Lexical transfer. In Aneta Pavlenko (ed.), The bilingual mental lexicon: Interdisciplinary approaches, 99-124. Bristol: Multilingual matters.

Jäger, Lena, Lena Benz, Jens Roeser, Bryan W. Dillon \& Shravan Vasishth. 2015. Teasing apart retrieval and encoding interference in the processing of anaphors. Frontiers in psychology. https://doi.org/10.3389/fpsyg.2015.00506

Kamp, Hans \& Uwe Reyle. 1993. From Discourse to Logic. Introduction to Modeltheoretic Semantics of Natural Language, Formal Logic and Discourse Representation Theory. Part 2. Dordrecht: Kluwer.

Kennison, Sheila M. 2003. Comprehending the pronouns her, him, and his: Implications for theories of referential processing. Journal of Memory and Language $49(3) .335-352$.

Koornneef, Arnout. 2008. Eye-catching Anaphora. Dissertation. Utrecht University Repository.

Kratzer, Angelika \& Irene Heim. 1998. Semantics in generative grammar. Oxford: Blackwell.

Lago, Sol, Anna Stutter Garcia \& Claudia Felser. 2018. The role of native and non-native grammars in the comprehension of possessive pronouns. Second Language Research 2018, 1-31. doi:10.1177/0267658318770491. 
McGregor, William (ed.). 2009. The expression of possession. Berlin: De Gruyter.

Nicol, Janet \& David Swinney. 1989. The role of structure in coreference assignment during sentence comprehension. Journal of Psycholinguistic Research 18. 5-2.

Pablos, Leticia, Jenny Doetjes, Bobby Ruijgrok \& Lisa L.-S. Cheng. 2015. Active search for antecedents in cataphoric pronoun resolution. Frontiers in psychology 6. doi: 10.3389/fpsyg.2015.01638.

Patil, Umesh, Shravan Vasishth \& Richard L. Lewis. 2016. Retrieval interference in syntactic processing: The case of reflexive binding in English. Frontiers in psychology 7. http://dx.doi.org/10.3389/fpsyg.2016.00329

Patterson, Clara, Helena Trompelt \& Claudia Felser. 2014. The online application of binding condition $\mathrm{B}$ in native and non-native pronoun resolution. Frontiers in psychology 5. 147.

Pitz, Anneliese, Berlgjot Behrens, Oliver Bott, Torgrim Solstad, Robin Hörnig \& Cathrine Fabricius-Hansen. 2017. An empirical L2 perspective on possessives: German/Norwegian. Oslo Studies in Language (OSLa) 9(2). 41-74.

Pozzan, Lucia \& Inés Antón-Méndez. 2017. English possessive gender agreement in production and comprehension: Similarities and differences between young monolingual English learners and adult Mandarin-English second language learners. Applied Psycholinguistics 38(4). 985-1017.

Roberts, Leah, Marianne Gullberg \& Peter Indefrey. 2008. Online pronoun resolution in L2 discourse: L1 influence and general learner effects. Studies in Second Language Acquisition, 30(3), 333-357.

Saad, Georg, Marian Klamer \& Francesca Moro. 2019. Identifying agents of change: Simplification of possessive marking in Abui-Malay bilinguals. Glossa:a journal of general linguistics. www.glossajournal.org/article/10.5334/gjgl.846/

Mikel Santesteban, Alice Foucart, Martin J. Pickering \& Holly Branigan. 2010. Is selection of possessive pronouns/ adjectives in L2 affected by L1 syntax? Unpublished poster presented at the 16th Annual Conference on Architectures and Mechanisms for Language Processing (AMLaP), York, UK.

Schimke, Sarah, Saveria Colonna, Israel de la Fuente \& Barbara Hemforth. 2015. L2 ambiguous pronoun resolution: The impact of L1-based preferences, L2 proficiency, \& working memory capacity. Presentation at ISB 10, Rutgers University. 
Schimke, Sarah, Israel de La Fuente, Barbara Hemforth \& Saveria Colonna. 2018. First Language Influence on Second Language Offline and Online Ambiguous Pronoun Resolution. Language Learning 68(3). 744-779.

Schulz, Miriam, Heather Burnett \& Barbara Hemforth. 2019. Rational Speech Act model of cross-linguistic differences in pronoun resolution preferences. Poster presented at the 32nd CUNY Conference on Human Sentence Processing. Boulder, Colorado, USA

Sturt, Patrick. 2003. The time-course of the application of binding constraints in reference resolution. Journal of Memory and Language 48 (3): 542-562.

Sturt, Patrick. 2013. Syntactic constraints on referential processing. In In Gompel, Roger G. P. van (ed.). Sentence processing, 136-159. Hove: Psychology Press.

Yu, Liming \& Terence Odlin (eds.). 2016. New perspectives on transfer in second language learning. Bristol: Multilingual Matters.

ZhaoHong, Han \& Elaine Tarone. 2014. Interlanguage: Forty Years Later. Amsterdam etc.: Benjamins.

\section{AC KNOWLEDGMENT}

We thank Oliver Bott for a critical and constructive review of an earlier version of this paper.

CONTACTS

Cathrine Fabricius-Hansen

University of Oslo, ILOS

c.f.hansen@ilos.uio.no

Anneliese Pitz

University of Oslo, ILOS

a.p.pitz@ilos.uio.no

Henrik Torgersen

University of Oslo, ILN

hatorger@uio.no 